\title{
Direct and Indirect Effects of Egg Quality Traits on Egg Weight of Potchefstroom Koekoek Chicken Genotype
}

\author{
Victoria Rankotsane Hlokoe and Thobela Louis Tyasi* \\ School of Agricultural and Environmental Sciences, Department of Agricultural Economics and Animal Production, \\ University of Limpopo, Private Bag X1106, Sovenga 0727, Limpopo, South Africa \\ *Corresponding author: louis.tyasi@ul.ac.za
}

Article History: 21-279 Received: 10-Feb-21 Revised: 26-Feb-21 Accepted: 01-Mar-21
ABS TRACT
Path analysis is the statistical tool used to assess the direct and indirect effects of independent variables on the dependent
variables. This study was done to examine the association among egg weight (EWt) and egg quality traits, including
egg length (EL), egg width (EWD), yolk weight (YW), shell weight (SW), shell ratio (SR), shell index (SI), albumen
weight (AW), albumen ratio (AR) and yolk ratio (YR), and assess the direct and indirect influences of egg quality traits
on egg weight. Three hundred eggs of Potchefstroom Koekoek chicken genotype were used in the study to determine
egg weight and egg quality traits. Pearson's association and path coefficient analysis were utilised for analysing data.
The findings of association showed that EWt had positively high statistically significant association (P $<0.01)$ with EL
(r=0.79), EWD (r=0.55), YW ( $r=0.45)$, AW ( $\mathrm{r}=0.48)$, and AR (r=0.38). Path analysis results revealed that YR $(-1.98)$
followed by YW (1.72) made the biggest direct influence on the EWt, while AR followed by SW displayed the highest
indirect effect on EWt via YR and YW. Correlation findings recommend that improving EL, EWD, YW, AW and AR
might result in increased EWt. The results of path analysis indicate that YR and YW could be selected during breeding
to improve EWt of Potchefstroom Koekoek chicken genotype. Chicken farmers may use the outcomes of the current
study to predict EWt using egg quality traits.

Key words: Direct effect, Indirect effect, Egg weight, Egg length, Yolk weight.

@202I IJVS - All Rights Reserved

\section{INTRODUCTION}

The Potchefstroom Koekoek is the chicken genotype which was bred through crossing of Black Australorp, White Leghorn and Barred Plymouth Rock (Grobbelaar et al. 2010; Tyasi et al. 2019). The genotype is adapted well to the tropical areas, have good self-sustainment, disease resistant, have brilliant temperament and suitable for freerange production system (Dessie and Gatachew 2016; Heit 2017). Potchefstroom Koekoek is a free-range dualpurpose chicken genotype used in communal farms in rural areas for meat and egg production (Mtileni et al. 2012; Idowu et al. 2018). However, the egg weight of this chicken genotype is low, hence, the egg quality traits require genetic improvement in order to enhance the egg weight (Mutibvu et al. 2019). According to Thakur and Bhardwaj (2017), path analysis is the statistical technique used to assess the cause-effect association among dependent and independent variables. Mendes et al. (2005) reported that path analysis analyses the direct and indirect impact of the independent variables on the dependent variables. Egg quality traits have been shown as important predictors of egg weight during breeding in South-eastern Nigeria local chicken (Adeolu and Oleforuh-Okoleh 2011), three varieties of Japanese quail (Chimezie et al. 2017) and Isa Brown egg layer chickens in Nigeria (Ukwu et al. 2017) and. However, based to our knowledge, the information on the prediction of egg weight from egg quality traits using path analysis in Potchefstroom Koekoek chickens genotype is not enough. Therefore, the objectives of the study were: 1) to determine the association between egg weight and egg quality traits, including egg length, egg width, yolk weight, shell weight, shell ratio, shell index, albumen weight, albumen ratio and yolk ratio using Pearson's correlation analysis, and 2) to determine the direct and indirect influences of egg quality traits on egg weight with path coefficient analysis. This research is going to assist Potchefstroom Koekoek chicken genotype farmers to select best egg quality traits that can be used to increase egg weight during breeding.

Cite This Article as: Hlokoe VR and Tyasi TL, 2021. Direct and indirect effects of egg quality traits on egg weight of Potchefstroom Koekoek chicken genotype. International Journal of Veterinary Science 10(4): 280-285. https://doi.org/10.47278/journal.ijvs/2021.053 


\section{MATERIALS AND METHODS}

\section{Ethical Approval}

This research was conducted following the standard operation procedures of the Animal Research and Ethics Committee (AREC) at the University of Limpopo, South Africa.

\section{Experimental Area}

The research was conducted at the University of Limpopo experimental farm. Brown and Ng'ambi (2019) explained the latitude, longitude, location, rainfall and ambient temperatures.

\section{Experimental Birds and Data Collection}

Eggs of Potchefstroom Koekoek chicken genotype were used in the study. A total of three hundred (300) eggs were collected and used for determining egg weight and egg quality traits. Egg weight was measured using a sensitive digital weighing balance (Mettler Toledo, PL203 CE) with accuracy of $0.001 \mathrm{~g}$. Egg length and egg width were taken using a Vernier calliper. Egg length (EL), egg width (EWD), yolk weight (YW), albumen weight (AW), shell weight (SW), shell index (SI), shell ratio (SR) and albumen ratio (AR) were measured and computed as described by Ukwu et al. (2017).

\section{Data Analysis}

Statistical Package for Social Sciences (IBM SPSS 2019) version 26 was employed for analysis of data. Descriptive statistics involving the coefficient of variation $(\mathrm{CV})$, mean and standard error of EWt were measured and computation of independent variables was done. Statistical Analysis System version 9.4 (SAS 2019) was used to plot the boxplot. To evaluate the relationship among measured traits, Pearson's correlation was used. Multiple regression was utilised to construct a formula for estimation of EWt using egg quality traits. The multiple linear regression model below was used:

$Y=a+b_{1} X_{1}+b_{2} X_{2}+b_{3} X_{3}+b_{4} X_{4}+b_{5} X_{5}+b_{6} X_{6}+b_{7}$ $\mathrm{X}_{7}+\mathrm{b}_{8} \mathrm{X}_{8}+\mathrm{b}_{9} \mathrm{X}_{9}$

\section{Where}

$\mathrm{Y}=$ dependent variable $(\mathrm{EWt})$,

$\mathrm{a}=$ intercept

$\mathrm{b}_{1}-\mathrm{b}_{9}=$ regression coefficient,

$\mathrm{X}_{1}-\mathrm{X}_{9}=$ independent variables (egg quality traits).

Path coefficient analysis method was employed to determine the direct and indirect influence of independent variables on the dependent variable as explained by Mendes et al. (2005). Path coefficient analysis was briefly calculated using the following formulas:

Pyxi $=\frac{\text { biSxi }}{\text { Sy }}$

\section{Where}

Pyxi = coefficient of path analysis from Xi to Y ( $\mathrm{i}=\mathrm{EL}$, EWD, YW, SW, SI, AW, AR, SR and YR)

bi $=$ partial coefficient of regression,

$\mathrm{Sxi}=$ standard deviation $(\sigma)$ of $\mathrm{Xi}$ and

Sy $=\sigma$ of $Y$.
Indirect effects of egg quality traits on EWt via direct influence were computed using the following formula:

IEyxi $=\operatorname{rxixjPyxj}$

Where

IEyxi = direct influence of egg quality traits through a direct influence on egg weight,

rxiyj = coefficient of correlation (r) among ith and jth egg quality traits, and

Pyxj = path analysis coefficient that shows the direct influence of jth egg quality trait on egg weight.

\section{RESULTS}

\section{Descriptive Statistics}

The summary about egg weight in Potchefstroom Koekoek chicken has been presented in Fig. 1. The egg weight values of all four quartiles i.e., $25^{\text {th }}$ (first quartile), $50^{\text {th }}$ (median) $75^{\text {th }}$ (third) and $100^{\text {th }}$ (maximum) have already been overviewed. Boxplot of EWt revealed minimum values greater than $50 \mathrm{~g}$, first quartile of $55 \mathrm{~g}$, median less than $60 \mathrm{~g}$, third quartile greater than $60 \mathrm{~g}$, and the maximum higher than $70 \mathrm{~g}$, respectively. The boxplot description showed that the data concerning EWt in Potchefstroom Koekoek had one outlier which was greater than $75 \mathrm{~g}$.

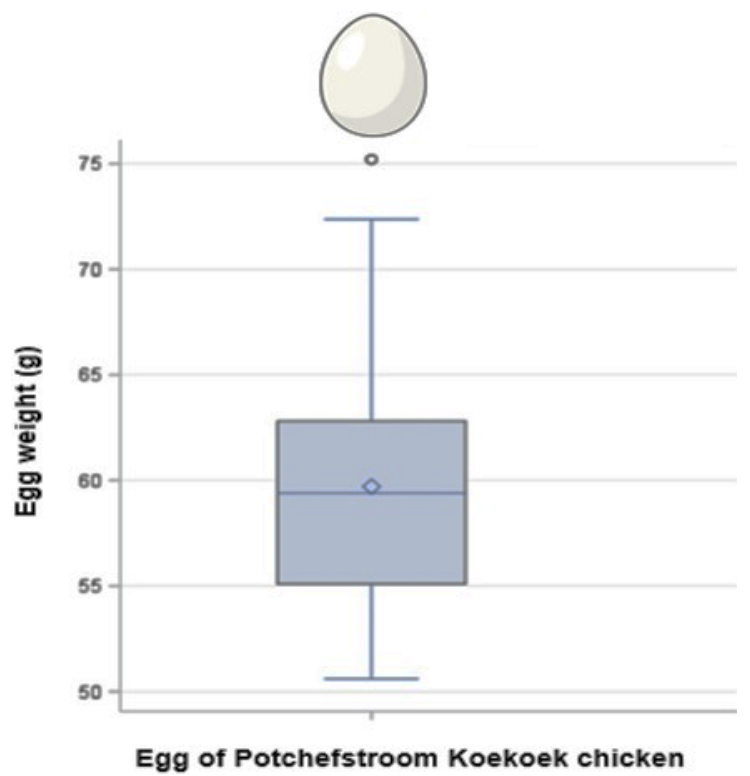

Fig. 1: Boxplot showing the median, minimum, maximum, 25th and 75th percentile values of egg weight of Potchefstroom Koekoek chicken.

The summary of EWt and egg quality traits including EL, egg EWD, YW, SW, SI, SR, AW, AR and YR is presented in Table 1. Descriptive statistics indicated that SI (73.56 \pm 1.02$)$ had greater mean values than all the other egg quality traits in Potchefstroom Koekoek chicken genotype, followed by EWt (59.71 \pm 0.32$)$, AR $(56.67 \pm 0.14)$, EL (55.56 \pm 0.12$)$ and EWD (43.45 \pm 0.07$)$, respectively. The results further showed that SW $(9.60 \pm 0.37)$ had the lowest mean numerical value than all the traits. The mean was divided with the standard deviation to calculate the coefficient of variance and the findings displayed a range of $3.71 \%-66.25 \%$. 
Table 1: Descriptive statistics for egg weight and egg quality traits of the Potchefstroom Koekoek chicken genotype

\begin{tabular}{lccc}
\hline Traits & $\mathrm{N}$ & Mean \pm SE & CV $(\%)$ \\
\hline EW $(\mathrm{g})$ & 300 & $59.71 \pm 0.32$ & 9.14 \\
EL $(\mathrm{mm})$ & 300 & $55.56 \pm 0.12$ & 3.71 \\
EWD $(\mathrm{mm})$ & 300 & $43.45 \pm 0.07$ & 2.83 \\
YW $(\mathrm{g})$ & 300 & $17.48 \pm 0.07$ & 7.21 \\
SW $(\mathrm{g})$ & 300 & $9.60 \pm 0.37$ & 66.25 \\
SI $(\%)$ & 300 & $73.56 \pm 1.02$ & 24.13 \\
SR $(\%)$ & 300 & $12.57 \pm 0.20$ & 27.53 \\
AW $(\mathrm{g})$ & 300 & $32.11 \pm 0.35$ & 18.78 \\
AR $(\%)$ & 300 & $56.67 \pm 0.14$ & 4.39 \\
YR $(\%)$ & 300 & $29.86 \pm 0.12$ & 7.17 \\
\hline
\end{tabular}

$\mathrm{EW}=$ egg weight, $\mathrm{EL}=$ egg length, $\mathrm{EWD}=$ egg width, $\mathrm{YW}=$ yolk weight, $\mathrm{SW}=$ shell weight, $\mathrm{SI}=$ shell surface index, $\mathrm{SR}=$ shell ratio, $\mathrm{AW}=$ albumen weight, $\mathrm{AR}=$ albumen ratio, $\mathrm{YR}=$ yolk ratio, $\mathrm{SE}=$ Standard error and $\mathrm{CV}=$ coefficient of variance.

\section{Phenotypic Correlations Between Measured Traits}

Pearson's association was employed to examine the relationship among EWt, and egg quality traits of Potchefstroom Koekoek chicken genotype and the findings are presented in Table 2. The results indicated that EWt had a positively high statistically significant correlation $(\mathrm{P}<0.01)$ with EL $(\mathrm{r}=0.79)$, EWD ( $\mathrm{r}=0.55)$, YW ( $\mathrm{r}=0.45)$, AW ( $\mathrm{r}=0.48)$, and AR ( $\mathrm{r}=0.38)$, and a negatively high statistically significant association $(\mathrm{P}<0.01)$ with $\mathrm{YR}(\mathrm{r}=-$ $0.49)$ and no significant correlation $(\mathrm{P}>0.05)$ with $\mathrm{SW}$ $(\mathrm{r}=0.04)$, SI $(\mathrm{r}=0.01)$ and SR $(\mathrm{r}=0.09)$. These findings further displayed that EL had a positively high statistical relationship $(\mathrm{P}<0.01)$ with EWD $(\mathrm{r}=0.49)$, YW ( $\mathrm{r}=0.57)$, AW ( $\mathrm{r}=0.42)$, and AR ( $\mathrm{r}=0.19)$, and a negatively high statistically significant association $(\mathrm{P}<0.01)$ with $\mathrm{YR}(\mathrm{r}=-$ $0.36)$ but not significantly associated $(\mathrm{P}>0.05)$ with $\mathrm{SW}$ $(r=0.08)$ and SI $(r=-0.05)$. The outcomes also indicated that EWD had a positively high statistically significant association $(\mathrm{P}<0.01)$ with $\mathrm{YW}(\mathrm{r}=0.28)$, AW $(\mathrm{r}=0.47)$, and AR ( $r=0.60)$, and a negatively high statistically significant correlation $(\mathrm{P}<0.01)$ with YR $(\mathrm{r}=-0.64)$ but had no significant association with $\mathrm{SW}(\mathrm{r}=0.08)$, SI $(\mathrm{r}=0.05)$ and $\mathrm{SR}(\mathrm{r}=0.03)$. The findings also showed that $\mathrm{YW}$ had a positively high statistically significant association $(\mathrm{P}<0.01)$ with YR ( $\mathrm{r}=0.38)$, and AW ( $\mathrm{r}=0.13)$ and a negatively high statistically significant association $(\mathrm{P}<0.01)$ with AR $(\mathrm{r}=-$ 0.43 ) but not statistically associated with SW ( $\mathrm{r}=0.05)$, SI $(r=-0.03)$ and SR $(r=0.09)$. The outcomes further showed that SI had a positively high statistically significant correlation $(\mathrm{P}<0.01)$ with SR $(\mathrm{r}=0.94)$, and AW $(\mathrm{r}=0.81)$ and no statistical significant correlation $(\mathrm{P}>0.05)$ with $\mathrm{AR}$ $(\mathrm{r}=0.06)$ and $\mathrm{YR}(\mathrm{r}=-0.03)$. SR had a positively high statistically significant association $(\mathrm{P}<0.01)$ with $\mathrm{AW}$ $(\mathrm{r}=0.77)$, a negatively high statistical significant association $(\mathrm{P}<0.01)$ with $\mathrm{AR} \quad(\mathrm{r}=-0.11)$ and not significantly associated $(\mathrm{P}>0.05)$ with $\mathrm{YR}(\mathrm{r}=0.04)$. AW had a positively high statistically significant association $(\mathrm{P}<0.01)$ with AR $(\mathrm{r}=0.44)$, and a negatively high statistically significant association $(\mathrm{P}<0.01)$ with $\mathrm{YR}(\mathrm{r}=-$ 0.46). Furthermore, AR had a negatively high statistically significant association $(\mathrm{P}<0.01)$ with $\mathrm{YR}(\mathrm{r}=-0.93)$.

\section{Multiple Linear Regression}

Multiple linear regression analysis was used to compute preliminary equations, and the results are described in Tables 3. The results showed that YW (8.274) had the greatest single contribution $(\mathrm{P}<0.05)$ to the EWt of Potchefstroom Koekoek chicken genotype followed by SR (0.196) with $\mathrm{R}^{2}=0.82$ and $\mathrm{MSE}=5.65$. The outcomes also displayed that $82 \%$ of the differences in EWt was described by the model. The model of multiple regression was constructed as EWt $=302.87-0.45 \mathrm{EL}-2.37 \mathrm{EWD}+8.27$ $\mathrm{YW}-1.68 \mathrm{SW}-0.24 \mathrm{SI}+0.20 \mathrm{SR}-1.38 \mathrm{AW}+0.04 \mathrm{AR}$ -6.22 YR. The findings showed that SR and AR in the model were statistically not significant $(\mathrm{P}>0.05)$.

\section{Path Analysis}

The value of regression coefficient from analysis of multiple regression was utilised as a direct effect of egg quality traits on EWt and an indirect influence was calculated with path coefficient analysis method. Path coefficient analysis results are presented in Tables 4 . The direct and indirect effects of egg quality traits on EWt of Potchefstroom Koekoek chicken genotype are shown in Table 4. The results showed that seven egg quality traits (EL, EWD, YW, SW, SI, AW and YR) were statistically significant as direct influences on EWt of Potchefstroom Koekoek chicken genotype. However, YR (-1.98) followed by YW (1.72) made the biggest direct influence on the EWt, while AR followed by SW displayed the highest indirect influence on EWt through YR and YW.

\section{Optimum Regression Model}

The best regression equation for estimation of EWt from egg quality traits of Potchefstroom Koekoek chicken was established. The findings of path analysis showed that coefficients of SR (0.20) and AR (0.04) were statistically non-significant, whereas EL (-0.33), EWD (-2.50), YW (8.21), SW (-1.59), SI (-0.17), AW (-1.38) and YR (-6.19) were statistically significant on the EWt. The statistically non-significant egg quality traits on the EWt were removed from the multiple linear regression model. The $\mathrm{R}^{2}$ and MSE

Table 2: Phenotypic correlation among measured egg quality traits

\begin{tabular}{|c|c|c|c|c|c|c|c|c|c|c|}
\hline Egg quality traits & EW & EL & EWD & YW & SW & SI & SR & AW & $\mathrm{AR}$ & YR \\
\hline \multicolumn{11}{|l|}{$\mathrm{EW}(\mathrm{g})$} \\
\hline $\mathrm{EL}(\mathrm{mm})$ & $0.79 * *$ & & & & & & & & & \\
\hline EWD (mm) & $0.55^{* *}$ & $0.49 * *$ & & & & & & & & \\
\hline YW (g) & $0.45^{* *}$ & $0.57 * *$ & $0.28 * *$ & & & & & & & \\
\hline SW (g) & $0.04^{\mathrm{ns}}$ & $0.08^{\mathrm{ns}}$ & $0.08^{\mathrm{ns}}$ & $0.05^{\mathrm{ns}}$ & & & & & & \\
\hline SI $(\%)$ & $0.01^{\mathrm{ns}}$ & $-0.05^{\mathrm{ns}}$ & $0.05^{\mathrm{ns}}$ & $-0.03^{\mathrm{ns}}$ & $-0.98 * *$ & & & & & \\
\hline SR $(\%)$ & $0.09^{\mathrm{ns}}$ & $0.11 *$ & $-0.03^{\mathrm{ns}}$ & $0.09^{\mathrm{ns}}$ & $-0.93 * *$ & $0.94 * *$ & & & & \\
\hline AW (g) & $0.48 * *$ & $0.42 * *$ & $0.47 * *$ & $0.13 * *$ & $-0.77 * *$ & $0.81 * *$ & $0.77 * *$ & & & \\
\hline $\operatorname{AR}(\%)$ & $0.38 * *$ & $0.19 * *$ & $0.60 * *$ & $-0.43 * *$ & -0.00 ns & $0.06^{\mathrm{ns}}$ & $-0.11 *$ & $0.44 * *$ & & \\
\hline YR (\%) & $-0.49 * *$ & $-0.36 * *$ & $-0.64 * *$ & $0.38 * *$ & $-0.05^{\mathrm{ns}}$ & $-0.03^{\mathrm{ns}}$ & $0.04^{\mathrm{ns}}$ & $-0.46 * *$ & $-0.93 * *$ & \\
\hline
\end{tabular}

$\mathrm{EW}=$ egg weight, EL=egg length, EWD=egg width, $\mathrm{YW}=$ yolk weight, $\mathrm{SW}=$ shell weight, $\mathrm{SI}=$ shell surface index, $\mathrm{SR}=$ shell ratio, $\mathrm{AW}=$ albumen weight, $\mathrm{AR}=$ albumen ratio, $\mathrm{YR}=$ yolk ratio, ns=not significant, * significant $(\mathrm{P}<0.05)$ and $* *$ significant $(\mathrm{P}<0.01)$. 
Int J Vet Sci, 2021, 10(4): 280-285.

Table 3: Multiple linear regression analysis for Potchefstroom Koekoek chicken genotype

\begin{tabular}{|c|c|c|c|c|c|c|c|c|c|}
\hline \multirow{2}{*}{$\begin{array}{l}\text { Regression } \\
\text { Parameters }\end{array}$} & \multicolumn{9}{|c|}{ Egg quality traits } \\
\hline & EL & EWD & YW & SW & SI & SR & AW & $\mathrm{AR}$ & YR \\
\hline Coefficient (B) & -0.45 & -2.37 & 8.27 & -1.68 & -0.24 & 0.20 & -1.38 & 0.04 & -6.22 \\
\hline SE & 0.22 & 0.33 & 0.95 & 0.50 & 0.11 & 0.41 & 0.38 & 0.46 & 1.08 \\
\hline P-value & 0.04 & 0.00 & 0.00 & 0.00 & 0.03 & 0.63 & 0.00 & 0.94 & 0.00 \\
\hline
\end{tabular}

Intercept (a) $=302.87$, Coefficient of determination $\left(\mathrm{R}^{2}\right)=0.82$, MSE $=5.65$

$\mathrm{EL}=$ egg length, $\mathrm{EWD}=$ egg width, $\mathrm{YW}=$ =yolk weight, $\mathrm{SW}=$ shell weight, $\mathrm{SI}=$ shell surface index, $\mathrm{SR}=$ shell ratio, $\mathrm{AW}=$ albumen weight, $\mathrm{AR}=$ albumen ratio, $\mathrm{YR}=$ yolk ratio.

Table 4: Path coefficient analysis of egg quality traits and egg weight

\begin{tabular}{|c|c|c|c|c|c|c|c|c|c|c|c|}
\hline \multirow[t]{2}{*}{ Egg quality traits } & \multirow{2}{*}{$\begin{array}{c}\text { Correlation } \\
\text { coefficient with EW }\end{array}$} & \multirow{2}{*}{$\begin{array}{l}\text { Direct } \\
\text { effect }\end{array}$} & \multicolumn{9}{|c|}{ Indirect effect } \\
\hline & & & EL & EWD & YW & SW & SI & SR & $\mathrm{AW}$ & $\mathrm{AR}$ & YR \\
\hline $\mathrm{EL}(\mathrm{mm})$ & $0.79 * *$ & $-0.20^{*}$ & & -0.26 & 0.98 & -0.11 & 0.05 & 0.04 & -0.46 & 0.04 & 0.71 \\
\hline EWD (mm) & $0.55 * *$ & $-0.54 *$ & -0.10 & & 0.48 & -0.12 & -0.05 & -0.01 & -0.51 & 0.13 & 1.26 \\
\hline YW (g) & $0.45^{* *}$ & $1.72 *$ & -0.11 & -0.15 & & -0.07 & 0.03 & 0.03 & -0.15 & -0.10 & -0.76 \\
\hline SW (g) & $0.04^{\mathrm{ns}}$ & $-1.41^{*}$ & -0.02 & -0.04 & 0.08 & & 0.86 & -0.36 & 0.84 & 0.00 & 0.11 \\
\hline SI $(\%)$ & $0.01^{\mathrm{ns}}$ & $-0.87 *$ & 0.01 & -0.03 & -0.05 & 1.39 & & 0.37 & -0.88 & 0.01 & 0.06 \\
\hline SR $(\%)$ & $0.09^{\mathrm{ns}}$ & $0.39^{\mathrm{ns}}$ & -0.02 & 0.01 & 0.15 & 1.31 & -0.82 & & -0.83 & -0.03 & -0.07 \\
\hline $\mathrm{AW}(\mathrm{g})$ & $0.48 * *$ & $-1.09^{*}$ & -0.09 & -0.25 & 0.23 & 1.09 & -0.71 & 0.30 & & 0.10 & 0.90 \\
\hline $\mathrm{AR}(\%)$ & $0.38 * *$ & $0.22^{\mathrm{ns}}$ & -0.04 & -0.32 & -0.75 & 0.00 & -0.06 & -0.04 & -0.47 & & 1.84 \\
\hline YR (\%) & $-0.49 * *$ & $-1.98^{*}$ & 0.07 & 0.34 & 0.66 & 0.08 & 0.03 & 0.01 & 0.50 & -0.20 & \\
\hline
\end{tabular}

$\mathrm{EW}=$ egg weight, $\mathrm{EL}=$ egg length, $\mathrm{EWD}=$ egg width, $\mathrm{YW}=$ yolk weight, $\mathrm{SW}=$ shell weight, $\mathrm{SI}=$ shell surface index, $\mathrm{SR}=$ shell ratio, $\mathrm{AW}=$ albumen weight, $\mathrm{AR}=$ albumen ratio, $\mathrm{YR}=\mathrm{yolk}$ ratio, ns=not significant, *significant $(\mathrm{P}<0.05)$ and $* *$ significant $(\mathrm{P}<0.01)$.

in the regression model were changed by the removal of statistically not significant egg quality traits. Table 5 presents the best regression models for estimation of EWt from egg quality traits of Potchefstroom Koekoek. The remaining egg quality traits were evaluated again with the multiple linear regression approach to estimate EWt after the exclusion of non-significant egg quality traits (SR and AR). The model of EL, EWD, YW, SW, SI, AW and YR was statistically significant $(P<0.05)$ with $R^{2}=0.82$ and $\mathrm{MSE}=5.63$. The equation of regression was constructed as $\mathrm{EWt}=300.59-0.33 \mathrm{EL}-2.50 \mathrm{EWD}+8.21 \mathrm{YW}-1.59 \mathrm{SW}$ -0.17 SI -1.38 AW -6.19 YR. This indicates that $82 \%$ of the variation in EWt was described by the model.

\section{DISCUSSION}

The egg quality traits are the best parameters in animal breeding for improvement of egg weight in chickens (Ukwu et al. 2017; Khaskheli et al. 2020). The boxplot was used to summarise the data for all studied traits and the results showed that the Potchefstroom Koekoek had egg weight of about 58g. Descriptive statistics further indicated that SI had greater mean values than other egg quality traits in Potchefstroom Koekoek chicken genotype, followed by EWt, AR, EL and EWD, respectively. The results were higher than that of Nonga et al. (2010) in Tanzania freerange local chickens, Mohammed et al. (2005) in Sudanese indigenous chicken ecotypes, Saroj et al. (2020) in indigenous Sakini chicken and Dzungwe et al. (2018) in French broiler Guinea fowl. The differences may be due to breed variations. This study firstly used Pearson's correlation to examine the relationship among EWt and egg quality traits namely, EL, EWD, YW, SW, SI, AW, AR, SR and YR in Potchefstroom Koekoek. The results indicated that EL, EWD, YW, AW and AR had a positively high statistically significant relationship with EWt. The results of this study showed that by enhancing EL, EWD, YW, AW and AR might result in improved EWt. Therefore, EL, EWD, YW, AW and AR might be involved in the criteria for selection during breeding to enhance EWt in Potchefstroom Koekoek chicken genotype. The findings of this study are in agreement with previous studies on South-eastern Nigeria local chicken (Adeolu and OleforuhOkoleh 2011), Isa Brown egg layer chickens in Nigeria (Ukwu et al. 2017), French broiler Guinea fowl (Dzungwe et al. 2018) and indigenous Sakini chicken Saroj et al. (2020). The results were dissimilar to those of Dayanidhi et al. (2016) in indigenous Hansli chickens, and the variations may be due to breed differences. Naskar et al. (2005) and Tyasi et al. (2017) reported that the coefficient of association only assists in specifying the size of relations without determining the cause effect relationship among the traits. Therefore, the use of path coefficient analysis method helps in examining the direct and indirect influences of the egg quality traits on EWt of Potchefstroom Koekoek.

Multiple linear regression analysis was used to calculate the path coefficient for egg quality traits. The equation of regression was constructed using the findings of multiple regression and all the measured egg quality traits were involved in the equations. However, EL, EWD, YW, SW, SI, AW and YR were statistically significant. The regression results agree with the study of Orhan et al. (2016) in commercial white layer hybrids of Isparta. The results show that EL, EWD, YW, SW, SI, AW and YR were statistically significant as direct influences on EWt of Potchefstroom Koekoek chicken genotype. Path coefficient analysis technique was employed to predict the indirect influence of egg quality traits on EWt. The findings revealed that YR followed by YW made the biggest direct influence on the EWt, while AR followed by SW displayed the highest indirect influence on EWt through YR and YW of Potchefstroom Koekoek chicken genotype. These results explain that YR and YW made the greatest influence on EWt of Potchefstroom Koekoek chicken genotype. The path analysis findings suggest that EWt could be estimated using YR and YW in Potchefstroom Koekoek chicken genotype. The egg quality traits that were not significant were excluded for construction of optimum regression model. Following the elimination of not significant egg 
quality traits from the model, EL, EWD, YW, SW, SI, AW and YR were included in the regression model. Based to the previous information, there are limited path analysis studies evaluating the relationship among EWt and egg quality traits in chickens. Nevertheless, most research of path coefficient analysis in chickens were focusing on enhancement of body weight in Chinese indigenous Dagu male chickens (Tyasi et al. 2018), indigenous Nigeria chickens (Egena et al. 2014), Taishan chickens (Qiao et al. 2017) and Zambian indigenous free-range chickens (Liswaniso et al. 2020). Other studies can use path analysis to investigate the cause effect association between EWt and egg quality traits in other chicken breeds.

\section{Conclusion}

The findings showed that there is correlation among egg quality traits. It is concluded that EL, EWD, YW, AW and AR had a high positive association with EWt of Potchefstroom Koekoek chicken genotype. Path analysis showed that YR and YW made the greatest direct effect on the EWt, while AR and SW made the biggest indirect influence on EWt through YR and YW of Potchefstroom Koekoek chicken genotype. This means that YR and YW made the highest contribution to EWt. The established regression model can be employed by chicken farmers to predict EWt. The study may help Potchefstroom Koekoek chicken farmers with traits to use as selection criterion during breeding to enhance egg weight. Additional studies are required to examine the association among egg weight and egg quality traits in larger sample of similar or varying chicken genotypes.

\section{Acknowledgements}

Authors wish to express their gratitude to the Farmworkers at the University of Limpopo Experimental for their support during data collection and Department of Agricultural Economics and Animal Production, the University of Limpopo for financial support.

\section{Author's Contribution}

TLT and HVR designed the experiment, analyzed the data the manuscript. HVR performed fieldwork and wrote the manuscript. TLT revised, read, edited and approved the final manuscript.

\section{REFERENCES}

Adeolu AI and Oleforuh-Okoleh VU, 2011. Phenotypic relations between egg weight and other egg quality traits of southeastern Nigeria local chicken. Nigerian Journal of Animal Production 7: 15-19.

Brown D and Ng'ambi JW, 2018. Effects of dietary Vachelia karroo leaf meal inclusion on meat quality and histological parameters in Pedi bucks fed a Setaria verticillata hay-based diet. Applied Ecology and Environmental Research 17: 2893-2909. http://doi.org/10.15666/aeer/1702_28932909

Chimezie VO, Fayeye TR, Ayorinde KL and Adebunmi A, 2017. Phenotypic correlations between egg weight and some egg quality traits in three varieties of Japanese quail. Agrosearch 1: 44-53. https://doi.org/10.4314/agrosh.v17i1.4

Dayanidhi B, Pradhan CR, Behura NC, Mohapatra LM, Mohanty GP, Behera K, Mishra SK, Panigrahy KK and Gupta SK, 2016. Evaluation of Egg Quality Traits in Indigenous Hansli Chicken of Odisha. International Journal of Agriculture Sciences 8: 2950-2953.
Dessie T and Gatachew F, 2016. The Potchefstroom Koekoek breed. International livestock research institute. https://doi. org/10.18805/ijar.B-944

Dzungwe JT, Gwaza DS and Egahi JO, 2018. Phenotypic correlation between egg weight and egg linear measurements of the French broiler guinea fowl raised in the humid zone of Nigeria. Current Trends on Biostatistics and Biometrics 1 http://doi.org/10.32474/CTBB.2018.01. 000104

Egena SSA, Ijaiya AT and Kolawole R, 2014. An assessment of the relationship between body weight and body measurements of indigenous Nigeria chickens (Gallus gallus domesticus) using path coefficient analysis. Livestock Research for Rural Development 26: Article \#51.

Grobbelaar JAN, Sutherland B and Molalakgotla NM, 2010. Egg production potentials of four indigenous chicken breeds in South Africa. Animal Genetic Resources 46: 25-32. https://doi.org/10.1017/S2078633610000664

Heit HL, 2017. A comparative study on the growth rates between outbred and inbred chickens. International Livestock Research Institute. https://doi.org/10.1016/j.aquaculture. 2004.08.039

Idowu PA, Mpayipheli M and Muchenje V, 2018. Practices, housing and diseases within indigenous poultry production in Eastern Cape, South Africa. Journal of Agricultural Science 10: 111-121. https://doi.org/10.5539/jas.v10n11p 111

Khaskheli AA, Khaskheli MI, Khaskheli AJ and Khaskheli AA, 2020. Dietary influence of Yucca schidigera on broilers and layers: A review. International Journal of Veterinary Science 9: 458-461.

Liswaniso S, Tyasi TL, Quin N, Sun X and Xu R, 2020. Assessment of the Relationship between Body Weight and linear body measurement Traits of Zambian indigenous freerange chickens using path analysis. Sylwan 164: 465-485.

Mendes M, Karabayir A and Pala A, 2005. Path analysis of the relationship between various body measures and live weight of American Bronze turkeys under three different lighting programs. Tarim Bilimleri Dergisi 11: 184-188. DOI: https://doi.org/10.1501/Tarimbil_0000000408

Mohammed MD, Abdalsalam YI, Kheir AM, Yu-Jin W and Hussein MH, 2005. Comparison of the egg characteristics of different Sudanese indigenous chicken types. International Journal of Poultry Science 4: 455-457. https://doi.org/ 10.3923/ijps.2005.455.457

Mtileni BJ, Muchadeyi FC, Maiwashe A, Chimonyo M and Dzama K, 2012. Conservation and utilization of indigenous chicken genetic resources in Southern Africa. World's Poultry Science Journal 68: 727-748. https://doi.org/ $\underline{10.1017 / S 0043933912000852}$

Mutibvu T, Chimonyo M and Halimani TE, 2019. Effect of strain, sex and rearing among carcass and fat yield of Naked Neck, Ovambo and Potchefstroom Koekoek chickens. Indian Journal of Animal Research 2: 50-53. https://doi.org/ 10.18805/ijar.B-944

Naskar S, Banik S and Tomar SS, 2005. Path analysis for total determination of selective value in sahiwal catile. Indian Journal for Animal Research 39: 107-110.

Nonga HE, Kajuna FF, Ngowi HA and Karimuribo ED, 2010. Physical egg quality characteristics of free-range local chickens in Morogoro municipality, Tanzania. Livestock Research for Rural Development 22.

Orhan H, Eyduran E, Tatliyer A and Saygici H, 2016. Prediction of egg weight from egg quality characteristics using ridge regression and regression tree methods. Revista Brasileira de Zootecnia 45: 380-385. https://doi.org/10.1590/S180692902016000700004

Qiao X, Wang N, Yang Y, Yang A, Zhang Q and Fan X, 2017. Establishment of optimum regression model and path analysis between liveweight and body size of Taishan chickens. China Poultry 39: 54-56. 
Int J Vet Sci, 2021, 10(4): 280-285.

Saroj S, Mana RK, Naba RD, Neena AG and Nirajan B, 2020. Evaluation of external and internal egg quality traits of indigenous Sakini chicken in different generations of selection. International Journal of Agriculture and Forestry 10: 41-48. https://doi.org/10.5923/j.ijaf.20201002.01

Thakur S and Bhardwaj N, 2017. Correlation and Path Analysis of Yield and its Components Plant Traits in Ricebean [Vigna umbellata (Thunb.) Ohwi and Ohashi]. International Journal of Current Microbiology and Applied Sciences 6: 32723278. https://doi.org/10.20546/ijcmas.2017.612.380

Tyasi T L, Norris D, Ng'ambi J W and Mabelebele M, 2019. Combining abilities and heterosis of body weight in a diallel cross from three South African indigenous chicken genotypes. Applied Ecology and Environmental Research 17: 9717-9723. https://doi.org/10.15666/aeer/1704 9717 $\underline{9723}$
Tyasi TL, Qin N, Jing Y, Mu F, Zhu H, Liu D, Yuan S and Xu R, 2017. Assessment of relationship between body weight and body measurement traits of indigenous Chinese Dagu chickens using path analysis. Indian Journal for Animal Research 51: 588-93. https://doi.org/10.18805/ijar.v0iOF. $\underline{6990}$

Tyasi TL, Xu R, Chen X, Niu X, Qin N, Sun X, Zhang F and Zhu $H$, 2018. Prediction of carcass weight from body measurement traits of Chinese indigenous Dagu male chickens using path coefficient analysis. Indian Journal Animal Science 88: 744-748.

Ukwu HO, Ezihe CO, Asaa SK and Anyogo ME, 2017. Effect of egg weight on external and internal egg quality traits of Isa Brown egg layer chickens in Nigeria. Journal of Animal Science and Veterinary Medicine 2: 126-132. https://doi. org/10.31248/JASVM2017.051 